\title{
Impact of Playing Video Games on Cognitive Functioning and Learning Styles of Adolecents
}

\begin{abstract}
Sumera Sattar ${ }^{1}$, Prof Dr. Yasmeen Iqbal ${ }^{2}$, Rehan Yousaf ${ }^{3}$
Abstract:

Video games are especially popular with teens as a form of entertainment and the time they spend playing video games has grown exponentially. The focus of previous studies remained on the negative effects of video games on teen's behavior. Whereas, the present study intended to explore the possible positive effects of video games. The main objective of this study was to evaluate the effect of video games on cognitive functions and learning style in school going teens. A cross-sectional research design was used to compare cognitive functions and learning style of teen game players and non-players. The cognitive functions, including memory, attention and executive functions of 80 teens were measured who were divided into two groups: those who played video games regularly $(\mathrm{n}=40)$ and those who did not play video games regularly $(\mathrm{n}=40)$. Other data, such as demographic data, medical information, types of video games, and time spent playing video games, were also collected through the questionnaire. Out of 80 respondents, $77.5 \%$ of teens were from private schools and $22.5 \%$ from public schools between the ages of 15 and $17(\mathrm{M}=15.6, \mathrm{SD}=0.575)$. Results indicated that visual memory and visual learning type scores were significantly better in the play group. Participants who were playing video games regularly indicated significant differences in visual type of learning $(\mathrm{p}=0.000)$. Whereas, no significant differences were found in aural learning $(\mathrm{p}=1.000)$ and verbal learning $(\mathrm{p}=1.000)$. Based on the results, it can be concluded that playing video games has a positive effect on the type of visual learning. Future studies could investigate more ranges of higher-order cognition, such as reasoning, and critical thinking to differentiate between different types of video games.
\end{abstract}

Keywords: Video Games, Cognitive Functions, Learning Style.

\section{Introduction}

There is still much research to be done on the effects of video games (VG) on cognitive functions $(\mathrm{CF})$ of teens and this is certainly an important group of study to consider. It is usually argued that the impact of VGs on teens' behavior and $\mathrm{CF}$ requires a changed perspective to better understand the potential negative effects as well as the benefits of these games [1]. It is important to consider these potential benefits, considering that the perspectives of these games have changed something of a late, different, sensible and social nature [2]. Even a core group of studies has started to emerge, usually in the last five years that records many benefits. These

${ }^{1}$ Lecturer health and physical education department, Lahore College for Women University Lahore.

${ }^{2}$ Department of Sports Science and physical education faculty of Allied Health Sciences The University of Lahore

${ }^{3}$ Manager Sports Health \&amp; Physical Education, COMSATS University, Islamabad, Lahore Campus

Corresponding Author: sumerasattargcu@yahoo.com 
findings suggest that playing VGs provides teens with clear and engaging social, intellectual, and exciting experiences. Furthermore, these experiments have been shown to improve learning in teens as reported by authors [3].

Playing VGs helps four crucial territories: mental, enticing, eager, and social advantages. By joining encounters from developmental, positive, and social examination, it very well may be inferred that playing VGs energize authentic benefits. Numerous analysts have given adequate confirmation and a speculative thinking to persuade new activities of investigation on the by and large ignored benefits of playing VGs. Though modestly little assessment has focused in on the upsides of playing VGs expressly, the limits and benefits of having VGs for the most influence have been perused for a significant long time.

Groundbreaking cerebrum research has since a long time back underscored the flexible components of playing VGs and in developmental mind science, the positive limit of playing has been a running subject for indisputably the most respected specialists in the field. Analysts propose that playing VGs licenses youths to investigate various roads with respect to their scholarly capacities and reenact elective eager outcomes, which would then have the option to accomplish their objectives outside the play setting [5] expressed that "playing VGs offers opportunities to young people to reproduce real conflicts, to work out ideal objectives for their own pleasure and to improve contrary feelings". Ongoing neuroscientific research with rodents proposes express frontal cortex instruments that help explain how playing VGs explicitly prompts the improvement of scholarly capacities as revealed by [6]. Test research office inspects show that playing VGs achieves the appearance of substance improvement factors in the bits of the frontal cortex that are made for significantly amicable activities, thus propelling the turn of events and progression of these areas. Despite a couple exceptional variables, comparative energetic subjects recognized in adolescents' play experiences (e.g., transcendence, nurturance, apprehension, and improvement) are similarly examined in PC games, considering huge scholarly, excited, and social capacities to be secured.

There are a lot of examinations demonstrating the impact of VGs with various subjects and objections. These games can be played with other truly existing players, or with countless other online players, alone, appropriately, or in a real sense, and are played on an assortment of gadgets, from consoles to PCs. Thinking about the individual extent of assessments, contingent upon how VGs can move, contingent upon their order, it is truly hard to make an expansive coherent characterization of contemporary games. In any case, to do a short examination concerning this examination. This consistent game plan is a key change. Like different games, other significant appraisals are changed, and powerfully, VG can be played socially and nonsensically, assistant, and all things considered, and the intricacy of the games relying upon the game kind. Where the player takes an interest in these particular gaming arrangements. Given this colossal positioning in $\mathrm{VG}$, acclaim alone can't be significant. Many top examiners in the field have revealed that "nobody can say more regarding the impacts of food than the impacts of PC games' or VGs [7]. From that point forward, rather than capturing VGs, rather than showing a steady contortion. "Gamer" alludes to individuals who play VGs dependably, longer than an hour daily. Unintentionally, playing VGs builds up a wide scope of mental capacities, as opposed to the standard inclination that playing $\mathrm{VG}$ isn't useful for young people direct [8.9].

The most persuading affirmation comes from starter considers that select clueless gamers and self-emphatically apportion them to play either a shooter game or such a VGs for an equivalent time span. Showed up contrastingly according to control people, those in the shooter game condition show speedier and more careful idea scattering, higher spatial goal in visual preparing, and improved mental turn limits [10]. A really scattered meta-assessment pondered that the 
spatial limits overhauls got from playing fiscally accessible shooter PC games are indistinguishable with the impacts of formal courses featured improving these tantamount limits. Further, this new meta-appraisal showed that spatial limits can be set up with VGs in a passably concise period, that these preparation benefits last all through an extensive time interval, and frantically, that these limits move to other spatial undertakings outside the VGs setting [11].

These planning peruses have essential consequences for tutoring and calling progression. A longitudinal assessment with a test set up the power of spatial capacities in predicting achievement in science, development, planning, and math. These topics have been more than once associated with long stretch job accomplishment and are expected to be especially fundamental in the next century [12]. Preliminary investigation has moreover displayed that these scholarly advantages show in quantifiable changes in neural planning and capability. For example, another utilitarian appealing resonation imaging study found that the frameworks that control thought assignment were less powerful during a troublesome model acknowledgment task in conventional gamers than in nongame's, driving the researchers to recommend that shooter game players relegate their attentional resources even more capably and channel out pointless information even more suitably [13].

As of late, there has been expanding interest in the potential impacts of VGs on different cognitive capacities. Cognitive load is a significant thought, especially for teens. The principle objective of this study was to survey the impact of VGs on CF and learning style in VGs players and non-players in the range of 15 and 17 years of age.

\section{Literature Review}

The following section is divided into two parts, which will discuss different studies conducted on the effects of playing VGs on teens' behavior and effects of playing VGs on $\mathrm{CF}$ of teens.
2.1 Effects of Playing Video Games on Teens

The authors in [14] represent that the legitimacy of the connection between VGs and aggressive conduct depends on feeble proof or uncertain outcomes. Numerous investigations have been directed on the connection between the VGs and aggressive conduct of players [15]. Authenticity from the point of view of VGs is isolated into two principle parts, graphical authenticity and social authenticity. Graphical authenticity is the capacity to shape and change individuals from this present reality to the virtual world with exceptionally top notch. Social authenticity is the capacity of an individual in the virtual world to act like a similar manner in genuine reality. The outcomes show that there is no huge impact of the authenticity of the VGs into the progressions that may occur for the players [16]. The authors in [17] lead test to explore the relationship between social authenticity in the games and the aggressive conduct in the players. The authors make analyzed the effect of two different types of VGs on aggressive conduct. The findings of this examination show that there was no increment in aggressive conduct of the players.

Late youth and early youthfulness address the most tedious between different ages in playing computer games. It's anything but a significant job in changing their character for great or more terrible. There are numerous valuable and useful or abused media and games that are coordinated toward this life stage [18]. To explain this connection, an examination on a gathering of kids matured from 6 to 11 from the European Union was directed. The investigation shows that there is no connection between the measure of time that the child spent on playing the computer games and the children's psychological wellness, passionate, Attention-Deficit or Hyperactivity Disorder, acts or companion relationship [19]. Another investigation was led for enormous scope Norwegian teenagers. In this investigation, it was shown that there is no connection between the measures of time went through playing with inward issues that 
may happen to the children with playing these games [20].

The authors [21] examined teen participants to identify with what VGs mean for the practices and feelings of players, regardless of whether this impact is good or negative. It has been shown that games may cause an assortment of changes on the players like aggressive conduct, negative or agreeable and consideration from the positive side. The gathered information from the player was viewed as the primary part in dissecting the character of the major part to discover the effect of the VGs on the player. This information was gathered by using two different methods. The first was called selfdetailing information, which depends on gathering the information by the player utilizing polls, studies, interviews or ethnographic perceptions either, previously, during or in the wake of playing the game. The subsequent way was brought in-game information collection, where the information was gathered straightforwardly from the player through the VGs (i.e. while playing). Most of studies infer that there was a connection between the VGs and the player's conduct. In these investigations, the specialists presume that the VGs affect the player character, similar to feelings, reflexes, practices, inspirations, needs, thinking way and approach interior and outside circumstances. Then again, there is another exploration indicating that the VGs had no effect on the players. The authors [22] supported their case in two angles. The first depending on the game type and the subsequent one depending on the time that the player spent playing a game.

A large number of studies of the past shed light on the fact that playing VGs really involves a basic scenario through which the value of power and aggression, hostility, stress, violence is validated, as reported by authors, [23]. For example, a study on the effects of VGs showed how teens used to play enthusiastically and they improved their communication with their family members. The association between teen's joy and their improvement in cheerful skills, social skills, and affirmation of friendship has also been determined by observational studies [24].

\subsection{Effects of Playing Video Games on Cognitions}

In many experiments, [25] effect of playing VGs was assessed in regular players with several tasks such as attention, comprehension, memory and concentration. Regular players always performed better at these tests than non-players. The increase of performance seems induced by the activity of playing VGs, since in another experiment, a control group didn't get involved in playing and the experimental group played were engaged in playing VGs for an hour a day. Afterwards, the experimental group performed better at several of the same tasks than the control group. Nevertheless, in other studies, VGs was used as the experimental setting, and changes were observed. In two experiments, Researchers [26] asked students to play "VGs for half an hour a day for one month. Their improvement at different tasks was measured, four of these tests were taken from the standardized test battery. The results indicated improvement in attention, memory, focus and comprehension.

More recently, [27] demonstrated the specificity of improved memory by playing VGs. In their setting, experienced VG players outperformed non-players at tasks related to memory, but not at a series of other cognitive capacity tests. In a second experiment, female students played one hour sessions of VGs and showed the same gain than control group on the same tests. They concluded that if a cognitive ability can be increased by playing VGs, it is likely very domain specific and could concern only specific representations. Authors [28] reported some improvements in the dynamic memory and concentration of school children. The gender was an issue as boys benefited more from the VGs than girls. But initial visual learning turned out to determine the influence of the playing sessions: participants' highly skilled children showed no gain with the playing of VGs. However, low skilled participants who played VGs for three sessions of an hour significantly improved at the post test. 
The list of studies assessing different cognitive aspects of participants is still long. The methodologies are rather comparable, they either compare regular VGs players to nonplayers on several tests, or they establish a pre and posttest method and ask participants to play in between. Depending on studies, control groups do not play or sometimes play a game considered to have no influence. However, in a study [29] the participants of the control group were assigned to play VGs and obtained no effect with them, while [30] found effects of playing "VGs both on attention and perceptual abilities.

Researchers [31] recently explored the effect of playing $\mathrm{VG}$ on learning and understanding using an active research methodology. The authors [32] have recently begun to focus on more interactive devices, although attempts to investigate the effects of VGs by asking adolescents to play an interactive game designed to improve attention and focus. Different learning conditions were proposed and the study underscored the importance of orientation for the retention and transfer of learned knowledge. Positive aspects of interactive game were found but under specific conditions. The game used was a multimedia simulation similar to a questionnaire and could be compared more to an educational entertainment product than to a real conventional type of VGs.

In order to study the learning potential of games, [33] used an interactive game to teach "Newton laws to school children". The modality of feedback to the participants was either in an animated graphics way or numeric displays. Results were in favor of graphical feedbacks improve comprehension and retention of the material. In another study, [34] the researchers presented several simulations as activities to learn. They discussed the importance of "serious play" as a goal for active and meaningful engagement by the participants. The findings showed that without multimedia explanations, the content from the VGs was not remembered.

In summary, three trends were identified in the cognitive research related to the playing of VGs according to the dimensions beyond the scope: cognitive abilities and skills, affective and motivational aspects, knowledge and content learning. In most of these studies, VGs were considered as promising new materials or tasks that can foster knowledge of the dimension under investigation.

\section{Methodology}

A cross-sectional comparative study was conducted to investigate cognitive functions and learning style in video game players and non-players. Cognitive functions, including memory, attention, and comprehension, were assessed in 80 adolescents who were playing VGs regularly and those who were not playing VGs regularly. The selection criteria was based on the number of hours a day being spent in playing VGS. Those who were spending an hour a day were inducted in the players group and those who were playing less frequently or not playing at all were inducted in the nonplayers group. Assessment of cognitive functioning was done using "The Cognitive Functioning Inventory" developed by Lorna and learning styles were measured using "Learning-Style inventory" developed by Ronne. Based upon the aforementioned purpose of study, the research null hypotheses were formulated as "there will be no significant differences in cognitive functioning of video game players and non-players" and "there will be no significant differences in learning styles of video game players and nonplayers"

\section{Results}

Results included descriptive analysis followed by the results of one-way Betweengroups ANOVA which determined if significant differences existed between the video game players and non-players.

Participants who were playing video games regularly indicated significant differences in cognitive functions including attention $(\mathrm{p}=0.000)$ planning $\quad(\mathrm{p}=0.000)$, comprehension $(\mathrm{p}=0.000)$, memory $(\mathrm{p}=0.000)$, and cognitive control $(\mathrm{p}=0.000)$ as shown in Table-1 and mean differences are shown in Figure-1 below. 
Table 1. Cognitive Functions

\begin{tabular}{cccccc}
\hline Cognitive Functioning & Sum of Squares & df & Mean Square & F & Sig. \\
Attention & 37.813 & 1 & 37.813 & 65.288 & .000 \\
Planning & 22.050 & 1 & 22.050 & 22.780 & .000 \\
Comprehension & 32.513 & 1 & 32.513 & 50.543 & .000 \\
Memory & 37.813 & 1 & 37.813 & 65.288 & .000 \\
Cognitive Control & 37.813 & 1 & 37.813 & 65.288 & .000 \\
\hline
\end{tabular}

Participants who were playing video games regularly indicated significant differences in visual type of learning $(\mathrm{p}=0.000)$. Whereas, no significant differences were found in other learning styles aural $(\mathrm{p}=1.000)$ and verbal $(\mathrm{p}=1.000)$.

Table 2. Learning Styles

\begin{tabular}{lrrrrr}
\hline \multicolumn{1}{c}{ Learning Styles } & Sum of Squares & df & \multicolumn{1}{c}{ Square } & \multicolumn{1}{c}{ F } & \multicolumn{1}{c}{ Sig. } \\
Visual & 37.813 & 1 & 37.813 & 65.288 & .000 \\
Aural & .000 & 1 & .000 & .000 & 1.000 \\
Verbal & .000 & 1 & .000 & .000 & 1.000 \\
\hline
\end{tabular}

\section{Discussion}

Previous examination proposes that playing VGs, in any event, for a generally brief timeframe, improves execution on various assignments that action visual and consideration abilities. A few investigations have discovered that having members play VGs can improve execution on research center assignments that, by all accounts, are not quite the same as the games they were approached to play [9]. Accordingly, the VGs experience seems to upgrade fundamental abilities that can be applied to novel assignments. The discoveries of the current investigation demonstrated that teens who played VGs showed better scores in intellectual capacities. The new ascent in interest in VGs as a methods for improving essential intellectual and perceptual abilities expands on past discoveries. For instance, playing VGs was found to altogether improve intellectual abilities in teenagers contrasted with nonplaying controls [12]. Abilities gained while playing VGs appeared to continue to different undertakings also. For instance, teens who played VGs performed better compared to controls on memory and comprehension [17]. Numerous VGs expected players to concentrate on different covering and requesting part assignments, so improved memory results from better consideration control.

Authors [18, 19, and 20] gave proof that VGs can improve execution in a progression of 
consideration and comprehension. Both players and non-players who were allowed a couple of long stretches of playing VGs exhibited predominant execution on the consideration squint errand, a proportion of consideration adaptability over the long haul. Studies showed that players additionally exhibited a more prominent flank impact, demonstrating more noteworthy visual resources and members who played VGs. Significantly, members who played VGs with comparative engine segments contrasted with different games yet with less requests for consideration didn't enhance these assignments. Most shockingly, the players who rehearsed on VGs exhibited a change in visual learning or the capacity to make fine separation decisions of outwardly soaked

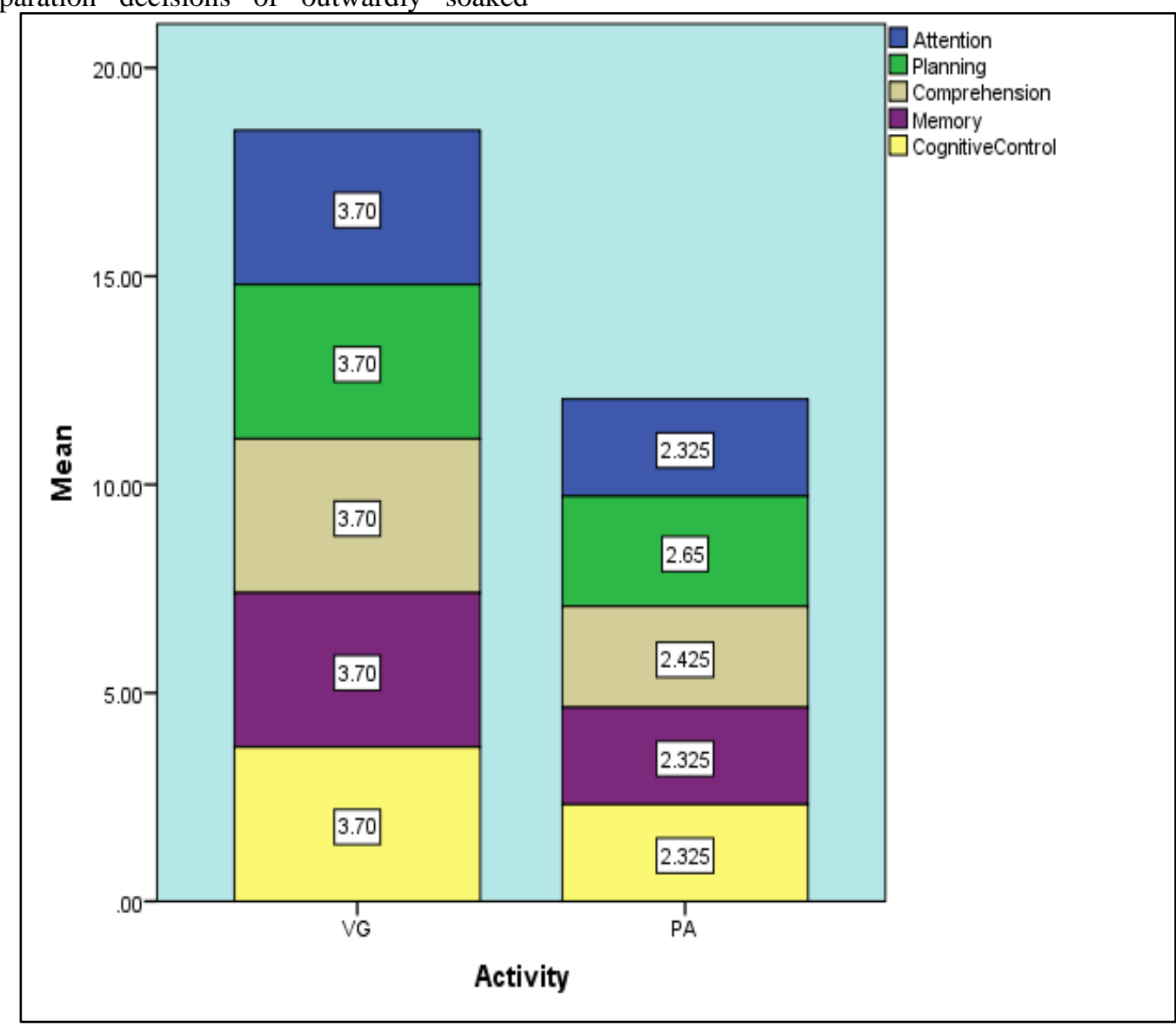

upgrades. Extra proof of the unrivaled presentation of VGs comes from crafted by, [13] showing that in a progression of errands, gamers exhibit quicker reaction times than non-gamers. At the point when taken together, these investigations recommend that playing VGs guarantees better execution in a wide assortment of circumstances; the exchange of the VGs experience gives off an impression of being broad. The exchange undertakings portrayed above were not quite the same as what the game members played on both the screens and the necessary reactions, however the exchange actually happened. 
The motivation behind this examination was to investigate whether the advantages of VGs are restricted to visual and consideration assignments, or whether the upgrades could be broader. Notwithstanding proportions of visual consideration, the impact of contacting VGs on various memory, thinking, and learning control assignments. It is realized that teens measure data diversely and the present circumstance influences the presentation of different intellectual capacities. It is currently all around acknowledged that VGs influence intellectual capacities and learning emphatically. In any case, it is completely difficult to carry out this beneficial outcome in clinical practice.

\section{Conclusion}

1. Based on the results, it can be concluded that playing video games has a positive effect on the type of visual learning. Future studies could investigate more ranges of higher-order cognition, such as reasoning, planning, and critical thinking to differentiate between different types of video games. This study has several limitations. First, due to the crosssectional nature, it is impossible to determine the direction of the associations between the data. Longitudinal studies will be needed to rule out possible cohort effects. Second, selfreported responses are open to many wellknown biases, such as social desire and memory recall biases, which can affect the veracity of the findings.

\section{REFERENCES}

[1] Herold, B. (2017). Poor Students Face Digital Divide in How Teachers Learn to Use Tech. Education Week. Retrieved from: https://www.edweek.org/ew/articles/2017/06/ 14/poor-students-face-digitaldivide- inteacher-technology-training.html

[2] Maheshwari, S. (2018). New pressure on Google and YouTube over children's data. The New York Times. Retrieved from https://www.nytimes.com/2018/09/20/busine ss/media/google-youtubechildren-data.html

[3] Bailey, J. O., \& Bailenson, J. N. (2017). Immersive virtual reality and the developing child. In F. Blumberg \& P. Brooks (Eds.), Cognitive development in digital contexts (pp. 181-200). Amsterdam, Netherlands: Elsevier.
[4] Kafai, Y. B., \& Burke, Q. (2015). Constructionist gaming: Understanding the benefits of making games for learning. Educational Psychologist, 50, 313-334.

[5] Bjørgen, A. M., \& Erstad, O. (2015). The connected child: Tracing digital literacy from school to leisure. Pedagogies, 10(2), 113-127.

[6] Anderson, M., \& Jiang, J. (2018). Teens' social media habits and experiences. Pew Research Center. Retrieved from http://www.pewinternet.org/2018/11/28/teens -social-media-habits-andexperiences

[7] Wood, C., \& Johnson, H. (2017). Digital childhoods and literacy development: Is textspeak a special case of an "efficient orthography"? In F. C. Blumberg, \& P. J. Brooks (Eds.), Cognitive development in digital contexts (pp. 201-216). New York, NY: Academic Press.

[8] Papathomas, L., \& Kuhn, D. (2017). Learning to argue via apprenticeship. Journal of Experimental Child Psychology, 159, 129139.

[9] Diamond, A., \& Liang, D. S. (2015). Conclusions about interventions, programs, and approaches for improving executive functions that appear justified and those that, despite much hype, do not. Developmental Cognitive Neuroscience, 18(2016), 34-48. https://doi.org/10.1016/j.den.2015.11.005

[10] Ricker, A. A., \& Richert, R. A. (2017). Digital gaming in middle-childhood: Examining game features that promote metacognition and memory. Paper presented at the Jean Piaget Society's Conference on Technologies and Human Development, San Francisco, CA.

[11] Takeuchi, L. M., \& Vaala, S. (2014). Level up learning: A national survey on teaching with digital games. New York, NY: The Joan Ganz Cooney Center at Sesame Workshop.

[12] Fisch, S. M. (2016). The capacity model, 2.0: Cognitive processing in children's comprehension of educational games. Paper presented at the Society for Research in Child Development Special Topic Meeting on Technology and Media in Children's Development. Irvine, CA.

[13] Revelle, G. (2013). Applying developmental theory and research to the creation of educational games. In F. C. Blumberg \& S. M. Fisch (Eds). Digital games: A context for cognitive development. New Directions for Child and Adolescent Development, 2013(139), 31-40.

[14] Allsop, Y. (2016). A reflective study into children's cognition when making computer games. British Journal of Educational Technology, 47, 665-679. 
[15] Staiano, A. E., Abraham, A. A., \& Calvert, S. L. (2012). Competitive versus cooperative exergames play for African American adolescents' executive function skills: Shortterm effects in a long-term training intervention. Developmental Psychology, $48(2)$, $337-342$. https://doi.org/10.1037/a0026938

[16] Bediou, B., Adams, D. M., Mayer, R. E., Tipton, E., Green, C. S., \& Bavelier, D. (2018). Meta-analysis of action video game impact on perceptual, attentional, and cognitive skills. Psychological Bulletin, 144(1), https://doi.org/10.1037/bul0000130

[17] Blumberg, F. C., Almonte, D. E., Barkhardori, Y., \& Leno, A. (2014). Academic lessons from video game play: What do we know and what should we know? In F. C. Blumberg (Ed.), Learning by playing: Video gaming in education (pp. 3-12). New York, NY: Oxford University Press.

[18] Lamb, R. L., Annetta, L., Firestone, J., \& Etopio, E. (2018). A meta-analysis with examination of moderators of student cognition, affect, and learning outcomes while using serious educational games, serious games, and simulations. Computers in Human Behavior, 80, 158-167.

[19] Lecce, S., Bianco, F., Devine, R. T., \& Hughes, C. (2017). Relations between theory of mind and executive function in middle childhood: A short-term longitudinal study. Journal of Experimental Child Psychology, $163,69-86$.

[20] Disney, L., Connelly, E., \& Waterhouse, B. (2017). Digital literacy - Teacher and parent conversations. Practical Literacy: The Early \& Primary Years, 22(3), 13-15.

[21] Deater-Deckard, K., El Mallah, S., Chang, M., Evans, M. A., \& Norton, A. (2014). Student behavioral engagement during mathematics educational video game instruction with 11-14 year olds. International Journal of ChildComputer Interaction, 2, 101-108.

[22] Gilligan, K. A., Flouri, E., \& Farran, E. K. (2017). The contribution of spatial ability to mathematics achievement in middle childhood. Journal of Experimental Child Psychology, 163, 107-125.

[23] Calvert, S. L. (2015). Children and digital media. In M. Bornstein \& T. Leventhal (Eds). Ecological settings and processes in developmental systems. In R. Lerner (Series ed.), Handbook of child psychology and developmental science, Vol. 7 (pp. 375-415). Hoboken, NJ: Wiley.

[24] Katz, B., Jaeggi, S. M., Buschkuehl, M., Stegman, A., \& Shah, P. (2014). Differential effect of motivational features on training improvements in school-based cognitive training. Frontiers in Human Neuroscience, 8, 242.

[25] Fisch, S. M., Lesh, R., Motoki, E., Crespo, S., \& Melfi, V. (2014). Cross-platform learning: How do children learn from multiple media? In F. C. Blumberg (Ed.), Learning by playing: Video gaming in education (pp. 207-219). New York, NY: Oxford University Press.

[26] Evans, M. A., Norton, A., Chang, M., DeaterDeckard, K., \& Balci, O. (2013). Youth and video games exploring effects on learning and engagement. Zeitschrift für Psychologie, 221, 98-106. Every Student Succeeds Act of 2015, 20 U.S.C. $\S 7119$.

[27] Weimer, A. A., Parault Dowds, S. J., Fabricius, W. V., Schwanenflugel, P. J., \& Suh, G. W. (2017). Development of constructivist theory of mind from middle childhood to early adulthood and its relation to social cognition and behavior. Journal of Experimental Child Psychology, 154, 28-45.

[28] Calvert, S. L., Putnam, M. M., Aguiar, N., Wright, C., Liu, A., Frolich, M., \& Barba, E. (2018). Intelligent media characters: Social meaningfulness and social contingency for teaching young children mathematics. Paper presented at the American Psychological Association Conference on Technology, Mind, \& Society, Washington, D.C.

[29] Wang, G., Taylor, L., \& Sun, Q. (2018). Families that play together stay together: Investigating family bonding through video games. New Media \& Society, 20, 4074-4094.

[30] Linder, J. R., \& Walsh, D. A. (2004). The effects of video game habits on adolescent hostility, aggressive behaviors, and school performance. Journal of adolescence, 27, 522.

[31] Prensky, M. (2005). Computer games and learning: digital game-based learning. In J. Raessens \& J. Goldstein (Eds.), Handbook of computer game studies. Cambridge: MIT Press.

[32] Durkin, K., \& Barber, B. (2002). Not so doomed: computer game play and positive adolescent development. Applied developmental psychology, 23, 373-392.

[33] Lynch, P. J., Linder, J. R., \& Walsh, D. A. (2004). The effects of video game habits on adolescent hostility, aggressive behaviors, and school performance. Journal of adolescence, 27, 5-22.

[34] Green, S. C., \& Bavelier, D. (2006). Enumeration versus multiple object tracking: the case of action video game players. Cognition, 101, 217-245. 
Sumera Sattar (et al.), Impact of Playing Video Games on Cognitive Functioning and Learning Styles of Adolecents

(pp. $49-58)$

[35] McFarlane, A., Sparrowhawk, A., \& Heald, Y.

(2002). Report on the educational use of games. Cambridge: TEEM.

Sukkur IBA Journal of Computing and Mathematical Science - SJCMS | Vol. 5 No. 2 July - December 2021 